\title{
Aplicação do Portfólio nas Escolas Médicas: Estudo de Revisão
}

\section{Application of the Portfolio in Brazilian Medical Schools: Integrative Review}

\author{
Maria Alice Amorim Garcia \\ Gabriela Egêa Alvaro do Nascimento II
}

\section{PALAVRAS-CHAVE \\ - Portfólio. \\ - Educação Médica. \\ - Avaliação Educacional.}

I Universidade Estadual Paulista Júlio de Mesquita Filho (Unesp), Botucatu, São Paulo, Brasil.

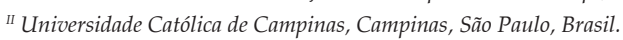

\begin{abstract}
RESUMO
Com o objetivo de formar um profissional crítico, criativo e reflexivo, novas propostas e reformulações vêm sendo criadas para o ensino médico, com base num processo educativo que promova o desenvolvimento de múltiplas competências. Buscando orientar a melhor atuação do estudante no processo ensino-aprendizagem, o portfólio fornece subsídios à reflexão, ampliando a capacidade de raciocínio, aliando o conhecimento teórico - adquirido em sala de aula e pesquisas - a vivências em serviços, territórios e demais cenários de aprendizagem. Englobando informações de diferentes estratégias pedagógicas, o portfólio possibilita maior autonomia, autoavaliação, criatividade, capacidade de crítica e de intervenção. Este estudo descreve a aplicação do portfólio nas escolas médicas brasileiras com base numa revisão de publicações científicas e do levantamento de projetos pedagógicos via internet. Procedeu-se a uma revisão integrativa de artigos científicos do período de 2007 a 2017, nas bases de dados da Biblioteca Virtual em Saúde (BVS), por meio dos descritores Portfólio AND Educação Médica, Portfólio AND Ensino, Portfólio AND Avaliação Educacional, e ao levantamento de projetos pedagógicos publicados na internet com citações referentes ao portfólio. Foram encontradas 19 publicações de investigações e 73 projetos pedagógicos acessíveis, entre os quais 38 citavam a palavra portfólio. Os conceitos de competências e narrativas permeiam parte expressiva dos trabalhos. Constatou-se que os portfólios são aplicados de forma muito diferenciada em cada escola, tanto como dispositivo de reflexão da prática, quanto como arquivo de trabalhos. As descrições referem-se à aplicação em determinadas disciplinas, em geral de práticas em serviços e comunidades e experimentos em situações focais. Por meio do portfólio, problematizam-se situações e estimula-se a reflexão e a busca de conhecimentos. Destaca-se o exercício da narrativa, que permite aliar a prática à teoria, facilitando a aprendizagem, além de ampliar a segurança e a habilidade do estudante - que precisa tomar decisões frente a situações reais, muitas vezes complexas -, fazendo com que este se torne um indivíduo ativo e crítico, com maior autonomia, intervindo na realidade. Comparando-se o número de projetos pedagógicos que citaram o uso do portfólio e as publicações encontradas, conclui-se que há grande carência de estudos voltados ao processo ensino-aprendizagem nas escolas médicas. Quanto aos achados a respeito da aplicação do portfólio, sobressaem as dificuldades relativas à manutenção do modelo biomédico nas escolas e métodos tradicionais de ensino e avaliação, bem como a falta de motivação e condições para que os docentes se dediquem a transformações que requerem capacitação, coesão e apoio institucional. Com a fragilidade na participação do professor e o excesso de tempo consumido na realização do portfólio, o estudante se depara com um instrumento que fomenta a autorreflexão e facilita seu aprendizado, mas também enfrenta a dificuldade de romper a barreira do ensino tradicional.
\end{abstract}




\section{KEY-WORDS}

- Portfolio.

- Education, Medical.

- Educational Measurement.

Recebido em: 5/9/2018

Aceito em: 25/9/2018
ABSTRACT

With the aim of producing professionals who are critical, creative and reflective, new proposals and reformulations have been created for Medical Education, based on an educational process that promotes the development of multiple skills. With the aim of guiding and improving students' performance in the teaching-learning process, the portfolio provides support for reflection, broadening their reasoning skills, and combining theoretical knowledge-acquired in the classroom and through research - with experiences in services, territories and other learning scenarios. Encompassing information from different pedagogical strategies creates greater autonomy, self-evaluation, creativity, critical and intervention capacity. This article describes the application of the portfolio in Brazilian medical schools, based on a review of scientific publications and a survey of pedagogical projects via the internet. An integrative review of scientific articles from the period 2007 to 2017 was conducted in the databases of the Virtual Health Library (BVS), using the search terms Portfolio AND Medical Education, Portfolio AND Teaching, Portfolio AND Educational Assessment, and a survey of pedagogical projects published on the internet with quotations related to the portfolio. A total of 19 publications of investigations and 73 pedagogical access projects were found, 38 of which cited the word portfolio. A significant part of this work addresses the concepts of skills and narratives. It was found that portfolios are applied differently in each school, both as a means of reflection on the practice, and as a work file. The descriptions given relate to its application in certain disciplines, generally practices in services and communities and experiences in focal situations. Through the portfolio, situations are investigated and a search for and reflection on knowledge are stimulated. The exercise of a narrative that links practice with theory, facilitating students' learning, is emphasized, as well as enhancing the confidence and ability of the student - who needs to make decisions in real, often complex situations - making him/her an active, critical individual, with greater autonomy, intervening in the reality. Comparing the number of pedagogical projects that cited the use of the portfolio with the number of publications found, it was concluded that there is a significant lack of studies that focus on the teaching-learning process in medical schools. Concerning the application of the portfolio, difficulties related to maintaining the biomedical model in schools, and traditional methods of teaching and evaluation, were highlighted, as well as the lack of motivation and conditions for teachers to engage in transformations that require training, cohesion and institutional support. With the lack of the teacher's participation, and the excessive time taken to carry out the portfolio, the student is provided with with an instrument that encourages self-reflection and facilitates learning, but also faces difficulty breaking away from a traditional teaching model.

\section{INTRODUÇÃO}

Há algumas décadas, nos fóruns de discussão e reflexão sobre a educação médica propiciados pela Associação Brasileira de Educação Médica (Abem) e outras entidades de ensino e atenção à saúde, acumulam-se argumentos favoráveis à necessidade de reorientar a formação desse profissional. Depara-se, entretanto, com determinantes diversos e complexos que dificultam essa mudança, entre eles: o papel social da profissão; o processo de acumulação capitalista em saúde, por meio, principalmente, da indústria de medicamentos, de equipamentos e insumos; a organização do trabalho e da atenção à saúde (pública e privada); as relações entre os profissionais, as equi- pes e os usuários; a situação da universidade em suas implicações com os outros segmentos sociais, seu papel na produção, distribuição e consumo do conhecimento, e na formação e educação permanente dos profissionais ${ }^{1}$.

Em relação à escola médica, é recorrente o diagnóstico de despreparo dos professores para atividades de docência e de investigação; a desarticulação entre teoria e prática, e entre ciclo básico e clínico; a hipervalorização das subespecialidades e do emprego de instrumentais tecnológicos; e a priorização de cenários de prática centrados em hospitais universitários e serviços próprios das universidades, muitas vezes descontextualizados do Sistema Único de Saúde (SUS) ${ }^{1-4}$. 
“Processos profundos de transformação na formação são complexos, envolvem mudanças conceituais, de posturas, de lugares e de relações institucionais, envolvem o enfrentamento de conhecimentos e valores cristalizados e hegemônicos e a construção de alternativas que não estão dadas. São processos que implicam conflitos, pressões e confrontações permanentes e que estão sob risco o tempo todo." (p. 13) ${ }^{1}$.

Quanto à aprendizagem, as mudanças, segundo Schraiber $^{2}$, devem incidir nas interações em diversos planos: entre o estudante e o paciente, entre o docente e outros profissionais, e entre o médico e seu saber. Há uma ruptura entre o médico e seu saber que anula a habilidade e disposição ética de refletir sobre sua própria ação na aplicação do saber científico-tecnológico diante de cada caso/contexto, o que a autora denomina "anulação da reflexividade".

Com a maior complexidade técnica, em razão da especialização e dos recursos instrumentais de intervenção, houve uma perda da dimensão pragmática da prática do médico, que passa a depositar toda a confiança nos meios tecnológicos e nas evidências científicas, deixando de confiar em seu saber tácito - ou a "arte de curar" - decorrente da experiência e juízo clínico pessoal².

Como analisado por Morin 5 , temos, na atualidade, que nos defrontar com a complexidade do conhecer e do pensar, que advém da incompletude do conhecimento, da sua mutilação e da simplificação ao ser despedaçado em disciplinas, categorias cognitivas e tipos de conhecimentos. Há uma inadequação entre os saberes fragmentados, disciplinares e a realidade cada vez mais complexa, o que torna invisíveis os conjuntos, as interações, as entidades multidimensionais, e, assim, os problemas essenciais. As escolas ensinam a dissociar os problemas do contexto.

Ainda segundo Morin 5 , "o aprendizado da auto-observação, faz parte do aprendizado da lucidez" (p. 53) ${ }^{5}$, e esta nos permite buscar a compreensão em sua complexidade, que tende para a multidimensionalidade e comporta em seu interior o princípio da incerteza e da incompletude, e, assim, do contínuo recomeço da aprendizagem, e o pensar, enquanto aptidão para organizar o conhecimento (p. 51)

Explicar não basta para compreender. [...] A compreensão humana nos chega quando sentimos e concebemos os humanos como sujeitos; ela nos torna abertos a seus sofrimentos e suas alegrias.

O educar enquanto desenvolvimento das aptidões gerais da mente (general problems setting and solving) permite o melhor desenvolvimento das competências particulares ou espe- cializadas. A aptidão interrogativa e a orientação para os problemas fundamentais de nossa própria condição e da época ampliam a capacidade de tratar problemas especiais ${ }^{5}$.

Cyrino (p. 781) ${ }^{6}$ destaca a importância da problematização que se apoia na aprendizagem por descoberta e significativa, valorizando o aprender a aprender.

Como desenvolvido por Freire ${ }^{7}$, a educação, enquanto prática da liberdade no contexto de ensino democrático, espírito crítico e compromisso social e com a cidadania, deve ser problematizadora e fundamentada na relação dialógica entre educador e educando, e não um depósito de conteúdos.

A educação problematizadora traz a dúvida, o conflito, a desconstrução, e parte de vivências de situações significativas. Por meio da descoberta, da reflexão, o estudante constrói as relações, os conteúdos, os conceitos, adaptando-os à sua estrutura cognitiva ${ }^{3,5-8}$.

As experiências tornam-se significativas quanto maior seu espaço de abrangência de aplicação do conhecimento ao real (internalização) e o nível de independência do imediato-concreto, ao se libertar do espaço e tempo presentes, fazer relações mentais na ausência das próprias coisas, para transformar, realizar sínteses, tomar posse do fazer e conhecer. Como analisa Garcia (p. 97)

É significativo, aquilo que marca, que se torna internalizado, que permite aproximar o que se conhecia ao novo, permitindo a mudança.

As discussões voltadas ao ensino médico indicam as atividades práticas em serviços e comunidades, os estágios e o internato como cenários privilegiados da intersecção ensino-trabalho e da problematização, condizentes com os princípios do SUS e com valores desejáveis para atuar no campo da saúde, tais como solidariedade, empatia, imaginação, criatividade, reflexão e crítica ${ }^{3,9}$.

De acordo com tais referências, passou-se a questionar a avaliação em sua centralidade como meta primeira do esforço dos alunos e professores, baseada quase exclusivamente em provas no final das disciplinas, centradas no cognitivo, com ênfase na memorização de conteúdos parciais e fragmentados e favorecedora da competitividade entre os estudantes ${ }^{1,10,11}$.

Condizentes com uma educação problematizadora, as avaliações devem configurar-se enquanto mediadoras do processo de aprendizagem, apresentando-se como formativas e somativas, úteis aos estudantes e docentes para identificar falhas e corrigir percursos, integrando as diferentes dimensões do aprendizado - cognitivas, de habilidades, comportamentais e éticas -, como também o desempenho do docente e a 
organização e o desenvolvimento do processo de ensino. Desta forma, a avaliação visaria a competências para lidar com a construção de conhecimentos e a resolução de problemas ${ }^{1,9,10,12}$.

Este esforço de inovação dos processos de ensino e avaliação tem apontado o portfólio como componente de um trabalho pedagógico reflexivo e participativo ${ }^{10,11}$.

Advindo do campo das artes, no âmbito escolar e universitário, o portfólio surgiu na década de 1990 nos EUA e vem sendo considerado pela Association for Supervision and Curriculum como um dos três melhores métodos de ensino-aprendizagem. Apresenta-se em todas as etapas da educação e no desenvolvimento profissional, com várias denominações de acordo com suas finalidades e contexto - porta-fólios, processo-fólios, diários de bordo, dossiê - e pode ser classificado como particular, de aprendizagem, demonstrativo e, recentemente, como webfólio ou portfólio digital ${ }^{10-14}$

Em revisão realizada por Bernardi et al. ${ }^{15}$, o portfólio apresenta-se em publicações relacionadas à avaliação de estudantes de graduação na área da saúde a partir de 1992. Dos 167 artigos encontrados nesta revisão, 29 (17,4\%) são de autores brasileiros, e 38 artigos dos Estados Unidos (22,7\%). O primeiro artigo brasileiro encontrado é de 2002, e as escolas médicas apresentaram $35,92 \%$ dos artigos, seguindo-se a Enfermagem, com 37,12\%.

Apropriando-se dos conceitos de Morin (p. 24-25) ${ }^{5}$, o portfólio é propício ao desenvolvimento do pensamento complexo, "ecologizante", situando o acontecimento e a informação em seu meio ambiente cultural, social, econômico, político e natural, levando em conta as relações e as inter-retroações entre cada fenômeno e seu contexto, as relações todo/partes.

Villas Boas ${ }^{16}$ ressalta que, por meio do portfólio, professor e aluno podem avaliar as atividades executadas durante um período de trabalho, levando em conta a trajetória percorrida. Não se aplica como avaliação classificatória ou punitiva, mas permite analisar o progresso do estudante, valorizando suas produções e comparando-as, de modo que se perceba o avanço obtido (p. 295) ${ }^{16}$ :

Isso requer que a construção do portfólio se baseie em propósitos de cuja formulação o aluno participe, para que se desenvolva o sentido de "pertencimento".

O uso do portfólio é um processo educativo em si mesmo, que, ao incorporar a autorreflexão, exige do estudante a aplicação de ferramentas cognitivas para ser capaz de compreender seu desenvolvimento, ou seja, a metacognição, que consiste na apropriação de representações internas do indivíduo acerca de suas emoções e formas de pensar e observar suas experiências, sua autovaloração ${ }^{11}$.
Funciona como um "dispositivo", segundo Stelet (p.168) , pois:

Não lida com uma estrutura fechada, organizada, cujos elementos em jogo estão previamente dados, mas, antes, com a ordem do imprevisível e da criação: o acontecimento e a experienciação.

Contando suas próprias histórias, mescladas às dos pacientes, o portfólio estimula narrativas que visam mobilizar o educando para a responsabilidade sobre seu processo de aprendizagem, favorecendo a análise de singularidades e peculiaridades do desenvolvimento de cada um ${ }^{9}$.

Considerando a amplitude, a transitoriedade, a dinamicidade do conhecimento e a complexidade do trabalho médico, a aplicação desse dispositivo torna-se relevante, pois permite ampliar a visibilidade do processo de ação-reflexão-ação, orientando a formação no sentido de possibilitar o aprender a aprender, o aprender a pensar, o aprender a fazer, o aprender a ser, o aprender a comunicar-se, o aprender a agir, o aprender a resolver problemas e o aprender a trabalhar em equipe. Estimulando a reflexão crítica sobre a prática no sentido de captar seus avanços, resistências e dificuldades, possibilita analisar as decisões sobre o que fazer, constituindo um instrumento eficaz para o desenvolvimento de atividades em cenários de práticas, em especial, nos serviços e na comunidade e $^{9,12,18}$.

Em sua revisão sistemática, Maia ${ }^{17}$ reconhece e agrupa os objetivos de uso do portfólio reflexivo em cinco categorias: avaliar e/ou acompanhar a aprendizagem; avaliar habilidades clínicas; avaliar e/ou documentar competências; possibilitar o desenvolvimento profissional continuado; estimular a reflexão.

Destaca-se o fato de que o portfólio privilegia o exercício da narrativa, que reativa o pensamento sobre as experiências do educando acerca de suas relações com o conhecimento científico, suas interações com o outro (paciente, equipe de saúde, tutor) e consigo mesmo. Quando o educador - preceptor, tutor, supervisor ou professor - estabelece uma relação com os educandos, estimulando a autonomia e a responsabilidade sobre o próprio aprendizado, ilustra o tipo de relação que se espera que desenvolvam com os usuários ${ }^{10,17,19}$.

É importante reafirmar o papel dos feedbacks no processo de desenvolvimento do portfólio, que consiste no diálogo entre professor e estudante, cumprindo a função transformadora desse dispositivo, de respeito à construção do estudante, sua capacidade de significação do aprendizado, do uso da intuição, da aquisição de estratégias múltiplas e flexíveis, da motivação e intencionalidade. 
Facilitando a utilização de métodos de informação e comunicação (TIC), o portfólio auxilia os futuros profissionais a responder às demandas da sociedade atual, referentes a compreender a informação, avaliar, criar, tomar decisões e solucionar problemas ${ }^{20}$.

Tem sido aplicado também na versão eletrônica, que apresenta as seguintes vantagens: facilidade para reorganizar, editar e combinar conteúdos; busca e acesso a conteúdos de forma não linear, usando hyperlinks, incluindo conteúdos de sua autoria e referências externas, o que facilita criar associações entre diferentes áreas do conhecimento; por ser "portável e móvel", permite transportar e transferir o conteúdo com facilidade e acessá-lo de locais diferentes, podendo ser compartilhado com outras pessoas, principalmente com os colegas e o preceptor ou docente ${ }^{21}$.

Com base nestas referências, este estudo visa sistematizar as produções relativas à aplicação dos portfólios como instrumento de aprendizagem e avaliação nas escolas médicas brasileiras. Não encontramos nenhuma publicação que realize esta revisão, embora o portfólio venha sendo empregado em várias escolas desde a promulgação das Diretrizes Curriculares Nacionais do Curso de Graduação em Medicina (DCN) de 2001.

Como descrito anteriormente, o portfólio apresenta-se enquanto instrumento que permite aos docentes e discentes, como também às equipes gestoras das escolas, uma avaliação do processo de aprendizagem e não somente seus resultados finais. Permite rever de forma integrada conhecimentos, habilidades e comportamentos adquiridos ou não nesse processo.

Considerando a proposição de seu uso nas DCN, questiona-se se vem sendo realmente empregado e quais são suas características, a fim de facilitar sua aplicação, ampliação ou aprimoramento, em especial nas escolas que têm optado pela aprendizagem baseada na problematização.

\section{MATERIAL E MÉTODOS}

Trata-se de uma revisão integrativa da literatura ${ }^{23,24}$, que visa combinar estudos teóricos e empíricos, incorporando definições e características referentes às aplicações do portfólio para o desenvolvimento de metodologias ativas de aprendizagem, descrevendo como vem sendo empregado, bem como as fragilidades e aspectos positivos desse processo, indicando as sugestões relatadas nas publicações.

De modo independente, os dois pesquisadores fizeram um levantamento de artigos do período de 2007 a 2017 nas bases de dados da Biblioteca Virtual em Saúde (BVS) por meio dos descritores: Portfólio AND Educação Médica, Portfólio AND Ensino, Portfólio AND Avaliação Educacional. Foram empregados como critérios de inclusão: publicações relativas a pesquisas ou relatos de experiências de cursos de graduação em Medicina brasileiros; reflexões e uma revisão relativas à aplicação do portfólio no ensino em saúde. Como critério de exclusão, a não definição nos artigos dos cursos da saúde envolvidos. Foram avaliados os seguintes itens: população e amostra do estudo, tipo de estudo ou investigação, aspectos positivos ou facilitadores do emprego do portfólio, aspectos negativos ou dificuldades de uso e sugestões apresentadas. Fez-se o levantamento de cada um desses itens em todos os artigos, buscando-se compilar aspectos que apresentavam semelhanças e discordâncias, para, desta forma, integrar os resultados. Computaram-se também quais artigos faziam referência às "competências" e "narrativas".

Enquanto estratégia de busca para a revisão, fez-se também o levantamento de projetos pedagógicos de escolas médicas brasileiras publicados na internet, buscando discriminar os que continham citações referentes ao portfólio, acessíveis de outubro de 2017 a março de 2018. Foram excluídos os sites das faculdades que não apresentavam os projetos pedagógicos ou não estavam acessíveis. Computou-se quantos citavam a palavra portfólio e se apenas se limitavam a esta citação. Entre os que apresentavam alguma descrição, buscou-se levantar a forma de aplicação do portfólio (se para aprendizagem, avaliação ou ambos), disciplinas, séries e caráter. Optou-se por não citar as referências dos projetos pedagógicos, por estarem em constantes mudanças e revisões e, em muitas situações, com acesso indisponível por questões técnicas.

\section{RESULTADOS}

Novos princípios de direcionamento do ensino médico surgiram com a Lei de Diretrizes e Bases da Educação Nacional, no 9.394/1996 (LDB), e Diretrizes Curriculares Nacionais do Curso de Graduação em Medicina (DCN) de 2001, atualizadas em 2014 ${ }^{22}$, indicando a formação de um profissional crítico, criativo e reflexivo, e um processo educativo que promova o desenvolvimento de múltiplas e complexas competências.

As DCN de $2014^{22}$ não se referem diretamente ao portfólio, mas se destacam alguns itens que indicam sua aplicação:

O Curso de Graduação em Medicina deverá utilizar metodologias ativas e critérios para acompanhamento e avaliação do processo ensino-aprendizagem e do próprio curso, bem como desenvolver instrumentos que verifiquem a estrutura, os processos e os resultados (artigo 32으.

Na seção Da Educação em Saúde:

O graduando deverá corresponsabilizar-se pela própria formação inicial, continuada e em serviço, autonomia intelec- 
tual, responsabilidade social [...] observando o dinamismo das mudanças sociais e científicas que afetam o cuidado e a formação dos profissionais de saúde, a partir dos processos de autoavaliação (artigo $7^{\circ}$, p. 3) $)^{22}$.

Na seção Da área de Competência de Educação em Saúde:

identificação das necessidades de aprendizagem próprias, das pessoas sob seus cuidados e responsáveis [...] a partir de uma situação significativa e respeitando o conhecimento prévio e o contexto sociocultural de cada um (artigo $20^{\circ}$, p. 9$)^{22}$.

\section{Projetos pedagógicos (PP)}

Foram encontrados, acessíveis via internet, de outubro de 2017 a março de 2018, 73 projetos pedagógicos, sendo que 38 citavam a palavra portfólio da seguinte forma:

- 41 projetos de universidades públicas federais, sendo que em 21 se encontrou a palavra portfólio; entre estes, em oito somente citada, e em 13 com alguma descrição de sua aplicação;

- 11 de escolas públicas estaduais, nas quais cinco citavam a palavra, três se limitavam a indicá-la como instrumento de avaliação de aprendizagem, e duas descreviam seu uso;

- 21 de escolas particulares com acesso via internet e projeto pedagógico acessível, sendo que em 12 a palavra portfólio foi encontrada, em quatro somente citada, e em oito com algum tipo de descrição da aplicação.

Constatou-se que a indicação do uso do portfólio vem aumentando, havendo um número crescente de descrições nos projetos das faculdades, em especial das universidades públicas federais e naqueles revistos ou implantados mais recentemente. Foram observadas descrições e fundamentações do uso desse instrumento em 23 dos projetos que citavam o portfólio, em que se destaca:

\section{Com relação à fundamentação didático-pedagógica}

- Enquanto abordagem educacional construtivista e instrumento de aprendizagem significativa, de caráter reflexivo;

- Visa dar conta de metodologias ativas de ensino com base na problematização, aprendizagem baseada em problemas (Problem Based Learning - PBL), aprendizagem baseada em projetos, metodologia da problema- tização usando o Arco de Maguerez, construção de Mapas Conceituais;

- Síntese de todo o processo de avaliação (somativo e formativo), visando abranger em amplitude e profundidade a análise das capacidades, construídas preferencialmente em ação ou vivências práticas.

Quanto às justificativas e objetivos

- O portfólio permite o acompanhamento do estudante e verifica o desenvolvimento e aquisição das competências, identificando as debilidades e permitindo estabelecer um plano de atividades para o enfrentamento dos desafios;

- Possibilita identificar os processos e os produtos de atividades;

- Estabelece um diálogo com os professores, e vice-versa, sobre avanços, dificuldades, angústias, e possibilita que os professores considerem o trabalho de forma processual.

Em relação às formas de aplicação

- Servir para anotar os principais conceitos dos temas estudados, interpretando-os;

- Incluir referências de aprendizagem diversificadas e a seleção representativa dos trabalhos produzidos pelo estudante;

- Ilustrar modos de trabalho nos vários cenários de práticas e/ou de estudos, como bibliotecas, laboratórios e outros;

- Apresentar mapas territoriais, fotografias, estudos teóricos, resenhas críticas;

- Como registro para o desenvolvimento de Trabalhos de Conclusão de Curso;

- Em disciplinas e módulos voltados à atuação na comunidade e serviços, nas atividades clínicas, nas áreas ou subáreas dos diferentes estágios, especialmente os relacionados à atenção básica em saúde;

- Como portfólio reflexivo eletrônico (PRE).

\section{Investigações e ensaios}

Foram selecionados 19 artigos que correspondiam aos critérios de pesquisa referentes a escolas médicas brasileiras e que tratam do uso do portfólio. Do total de 23 publicações, excluíram-se quatro que não se referiam ao curso médico.

Os resultados encontram-se resumidos nos Quadros 1 e 2 e discriminados quanto a forma de aplicação do portfólio, 
aspectos positivos, facilitadores ou vantagens de seu uso, aspectos negativos ou dificultadores e sugestões apontadas.

Constata-se a recorrência da utilização do conceito de "competências"11,20,22,25,26 em 15 do total de 19 artigos, e de "narrativas" "17, 19, 27 em oito artigos, que correspondem a referenciais da aplicação do portfólio, conforme apresentado na introdução. Há também a assertiva do caráter reflexivo em dez dos artigos.

Nesse quadro, pode-se observar que as publicações são escassas e limitadas a somente dez escolas, comparando-se com os 38 projetos pedagógicos que citaram sua utilização e as 279 escolas criadas no Brasil até dezembro de 2016.

\section{Formas de aplicação do portfólio}

- Arquiva e integra informações, tais como registros de visitas, entrevistas, projetos, relatórios, anotações individuais, mapas conceituais, fotografias, condução de reuniões ${ }^{4,17,18,28,29,32}$;

- Instrumento de comunicação para acompanhar o desenvolvimento do estudante com registro sucessi- vo dos ciclos pedagógicos ou de aprendizagem, por meio de discurso narrativo: descrições iniciais, sínteses provisórias, discussões, busca de informações e novas sínteses ${ }^{4,17,28,29,32}$;

- Dispositivo para o processo de retroação (feedback) pelo docente/ preceptor, que enriquece com novas informações e novas perspectivas ${ }^{4,13,17,28,29,32,33,35}$;

- Facilitador de buscas, pois possibilita organizar os conhecimentos $^{17,18,29}$;

- Para aquisição de habilidades de comunicação ${ }^{32,33}$;

- Dispositivo para a autoavaliação de atitudes e habilidades relativas às atividades e relações interpessoais nos serviços de saúde ${ }^{4,18,25,28,29,32}$;

- Em disciplinas na comunidade ou serviços de saúde, no ciclo pré-clínico ou internato, auxiliando na organização e acompanhamento da evolução dos planos de cuidado, como dossiê, planilha, diário de atividades ou relação de $\operatorname{casos}^{4,18,25,28,29,31-34 \text {; }}$

- Como portfólio reflexivo eletrônico (PRE) ou através de plataforma virtual ${ }^{17,21}$

QUADRO 1

Estudos analisados acerca da aplicação do portfólio nas escolas médicas

\begin{tabular}{|c|c|c|c|}
\hline Autor/ano & Revista & Escola & Cursos \\
\hline Moreto et al. $(2008)^{30}$ & Persona y Bioética & $8 \mathrm{FM}^{*}$ & Medicina \\
\hline Silva e Francisco $(2009)^{33}$ & Rev. Bras. Ed. Médica & Ufscar & Medicina \\
\hline Marin et al. $(2010)^{4}$ & Rev. Bras. Ed. Médica & Famema & Medicina \\
\hline Prearo et al. $(2011)^{32}$ & Rev. Bras. Ed. Médica & Unesp-Botucatu & Med., Enf. \\
\hline Zeferino et al. $(2012)^{34}$ & Rev. Bras. Ed. Médica & Unicamp & Medicina \\
\hline Fernandes et al. $(2013)^{35}$ & Rev. Paul. Pediatr. & FM Catanduva & Medicina \\
\hline Gomes e Rego $(2014)^{8}$ & Rev. Bras. Ed. Médica & UFV/Fiocruz & Medicina \\
\hline Maia e Struchiner (2016) ${ }^{17}$ & Rev. Bras. Ed. Médica & UFRJ & Medicina \\
\hline Forte et al. $(2016)^{21}$ & Rev. Bras. Ed. Médica & Ufscar & Medicina \\
\hline Troncon $(2016)^{36}$ & Rev. Grad. USP & FMRP & Medicina \\
\hline Stelet et al. $(2017)^{9}$ & Interface & UFRJ & Medicina \\
\hline
\end{tabular}

Legenda: Med.: Medicina; Enf.: Enfermagem; Nutri.: Nutrição; FM: Faculdade de Medicina.

* Instituições de ensino superior: Jundiaí, Vale do Itajaí, Nove de Julho, Católica de Goiânia

Escolas: UEL - Universidade Estadual de Londrina; UFSCAR - Universidade Federal de São Carlos; Famema - Faculdade de Medicina de Marília; UNICAMP - Universidade Estadual de Campinas; UNESP- Universidade Estadual Paulista; UFRJ - Universidade Federal do Rio de Janeiro; UFV - Universidade Federal de Viçosa; UFMG - Universidade Federal de Minas Gerais; UFC - Universidade Federal do Ceará; USP-FMRP-Universidade de São Paulo, Faculdade de Medicina de Ribeirão Preto; Faimer - Foundation for Advancement of International Medical Education and Research. 


\section{Aspectos positivos ou facilitadores}

\section{Fundamentos educacionais}

- Insere-se numa abordagem socioconstrutivista da educação que proporciona condições para aprender a fazer, agir, operar, criar, construir a partir da realidade vivida de situações-problema concretos ${ }^{29}$;

- Faculta ao estudante oportunidades para refletir, diagnosticar suas dificuldades, autoavaliar seu desempenho e autorregular, num processo contínuo,

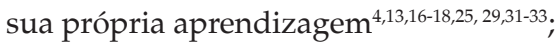

- Permite a individualização do estudante ${ }^{17,29,33}$, assumindo uma dimensão metacognitiva no seu desenvolvimento $^{29}$;

- Aplica-se na avaliação formativa norteada pela subjetividade, que permite equacionar conflitos cognitivos, afetivos e psicomotores, lacunas científicas ou omissões, garantindo condições de ampliar a compreensão e o desenvolvimento progressivo dos níveis de consciência e, por conseguinte, da autonomia e identidade do estudante ${ }^{4,29,32}$;

- No caso das narrativas referentes às situações da prática profissional, apresenta enfoque reflexivo de diferentes níveis - técnico, prático, crítico e metacrítico - que, nesta ordem, representam o maior aprofundamento da autorreflexão ${ }^{29}$.

\section{$\underline{\text { Finalidades }}$}

- Estímulo ao comprometimento com os princípios e diretrizes do SUS, fazendo com que os alunos tomem consciência do papel profissional e cidadão, e aprendam a ter cuidado com as necessidades de saúde individuais e coletivas ${ }^{4,20,25,28,29}$;

- Facilita a interdisciplinaridade, atrelando prática e teoria e melhor organização e gestão do trabalho em saúde 28,29

- Proporciona maior liberdade de criação e de tomada de decisão sobre o que fazer para superar obstáculos $^{4,29}$;

- Apresenta-se enquanto espaço de construção da profissionalidade, crítica e reflexiva, como processo afetivo, cultural, social e comunicacional ${ }^{29,33}$;

- Permite ao aluno atender em contextos diferentes, criar responsabilidade, aprender a trabalhar em equipe, desenvolver a compreensão da interação entre o social e o individual, valorizar o vínculo com o paciente, melhorando, desta forma, a integralidade das ações e, por consequência, o aprendizado humanizado $25,28,30-32,34,35$;
- Proporciona uma troca de informações para aprender a como trabalhar em grupo e desenvolver habilidades de comunicação, escuta e compreensão, podendo constituir uma rede de apoio social importante ${ }^{33}$;

- Em relação ao portfólio eletrônico, registra-se: auxílio na organização dos dados coletados e inclusão de esquemas e imagens; facilidade de busca, leitura dos textos e compartilhamento de informações entre os integrantes dos grupos e o preceptor ou professor ${ }^{2}$.

\section{Aspectos da docência e preceptoria}

- Exige um papel distinto, trabalhoso e complexo do docente/preceptor, que deve continuadamente propor questões que despertem no estudante o aprofundamento do seu pensar reflexivo e a implicação na procura de informação específica que corresponda ao seu processo de construção de conhecimento ${ }^{29}$;

- Amplia a percepção dos docentes acerca do desenvolvimento ético-formativo dos estudantes ${ }^{30}$.

\section{Aspectos negativos ou dificultadores}

- Resistência para romper a barreira teórica e o método tradicional de avaliação, decorrente da manutenção do modelo biomédico ${ }^{4,30,34}$;

- A não aceitação da subjetividade do processo, que implica apreensão, insegurança e rejeição por parte dos docentes e estudantes, principalmente no que se refere ao processo reflexivo ${ }^{4,32,33,35}$;

- Considerado muito trabalhoso, despendendo muito tempo e apresentando grande acúmulo de informações, que nem sempre são discutidas e aproveita-

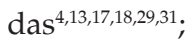

- Falta de orientação e demora ou falta de feedback por parte dos preceptores/professores ${ }^{17,32}$;

- Despreparo do docente e do estudante e falta de roteiros ou instrumentos padronizados de elaboração e de correção ${ }^{13,25,32,34}$;

- No caso do PRE, apresentam-se dificuldades relacionadas ao sistema operacional, coleta e armazenamento dos dados, receio quanto a roubo do equipamento, dificuldade de uso nos atendimentos por se entender que representa uma barreira na relação com os pacientes $^{21}$

- Insegurança e dúvida quanto ao consentimento e invasão de privacidade dos pacientes ${ }^{31}$. 


\section{Sugestões}

- Capacitação periódica, apoio institucional e suporte efetivo aos docentes / preceptores ${ }^{4,13,20,21,29,30 \text {; }}$

- Desenvolvimento de capacidades metarreflexivas e metacognitivas que permitam melhor aplicação e tempo de dedicação de estudantes e docentes ${ }^{29}$;

- Criação de espaços formais de feedback professor-aluno para avaliação, análise, discussão e revisão dos portfólios $4,13,17,32$;

- Proposta clara de estruturação e avaliação para orientação dos discentes por meio de modelos, exemplos, roteiros de elaboração e questionários de avaliação $\mathrm{o}^{21,32,34}$;

- Acompanhamento do processo de inclusão e desenvolvimento em novas disciplinas ${ }^{33}$;

- Aplicação no internato, sobretudo por oferecer oportunidades de interatividade e desenvolvimento da autonomia dos alunos sobre seu próprio aprendizado ${ }^{17}$;

- Implementação de estudos para a avaliação da aplicação do portfólio e sua influência na prática profissional ${ }^{33}$.

\section{DISCUSSÃO}

Nos processos de transformação no ensino universitário, em especial nas escolas médicas, enfrentam-se barreiras que culminam na resistência a mudanças curriculares e a alterações que possam repercutir em estruturas cristalizadas, como os processos de ensino e avaliação. A maior parte das escolas mantêm departamentos que não se articulam e estruturas de gestão hierarquizadas. Por sua vez, as normas universitárias em relação a notas e critérios de progresso, geralmente, são rígidas e quantitativas ${ }^{1}$.

As Novas Diretrizes Curriculares para os Cursos de Medicina $^{22}$ e demais proposituras advindas do Estado buscam promover as mudanças necessárias, em resposta às insatisfações geradas na sociedade. A reorientação das práticas de avaliação exige transformações curriculares e pedagógicas, bem como um corpo docente capacitado, coeso e com dedicação para implementar sistematicamente a evolução e o desenvolvimento de práticas, processos e procedimentos ${ }^{11,28,32}$.

Todas as investigações analisadas apontam um somatório de problemas na implantação de mudanças na aprendizagem e avaliação, destacando-se a resistência, o despreparo e a falta de condições para que o docente desenvolva esses processos.

Tratando-se da implantação do portfólio, estas dificuldades se exacerbam, por ser trabalhoso e depender do rompimento com o modelo biomédico, dominante nas escolas médicas ${ }^{4,13,17,18,28,29}$.

Predominam nas escolas os processos tradicionais de aulas magistrais e avaliações centradas em aspectos cognitivos quantitativos, pautadas no padrão certo/errado, sem estímulo à livre expressão dos alunos, que se preocupam em satisfazer as expectativas do professor, tomadas de modo absoluto ${ }^{10,13,14}$.

Uma preocupação corrente do estudante e também de muitos professores é a nota, que não cabe no enfoque avaliativo qualitativo e reflexivo. A produção do estudante por meio do portfólio aponta a construção de processos de ensino, e não de produtos ${ }^{13,18,35}$.

Nestes estudos, constatou-se que nos portfólios preponderam abordagens descritivas, sustentadas teoricamente ou baseadas no senso comum em detrimento de marcas reflexivas e contextualizadas. Apresentam-se fragilidades comunicacionais e organizacionais, como também resistência à subjetivação $0^{2,10,28,29,30,34,35}$.

Demonstrou-se, todavia, que a aplicação adequada do portfólio proporciona autoavaliação, autonomia e liberdade de criação, responsabilizando o estudante por seu próprio desenvolvimento ${ }^{4,12-14,17,28,29,32,33}$. Propicia também a aproximação das situações geradas nas relações com as equipes dos serviços de saúde e com os pacientes ${ }^{30-32,35}$.

Como sugerido nos artigos, a elaboração do portfólio pode ser facilitada pelo registro diário das atividades pelos estudantes (logbook, segundo Troncon) e por roteiros estrutu$\operatorname{rados}^{13,31,32}$, com a inserção periódica das reflexões, discutidas com o docente que realiza o feedback e auxilia no desenvolvimento da autoavaliação, reflexão e revisão de habilidades, comportamentos e conteúdos ${ }^{32,36}$.

Fundamentado na problematização, o portfólio apresenta-se enquanto dispositivo para (p. 785) ${ }^{6}$ :

\begin{abstract}
encorajar os alunos, em cada etapa de sua experiência de aprendizagem, a refletirem sobre a situação global de estudo de uma realidade concreta, com seus conflitos e contradições [...] volta-se com o fito de questionar o quanto determinada experiência mudou a compreensão, a apreensão, as atitudes e o comportamento [...] visando à consciência crítica.
\end{abstract}

Em seu caráter reflexivo, o portfólio abre a possibilidade de articular a explicação e a compreensão. A explicação, como explicita Morin (p. 93)5 , é objetiva, ou seja, considera as formas, qualidades, quantidades, e tem uma causalidade mecânica determinística. Já a compreensão funda-se na comunicação e empatia, na intersubjetividade, na identificação e projeção, necessitando abertura e generosidade.

Esse processo de compreensão é facilitado pela elaboração de narrativas, o que requer uma combinação de habilidades textuais (identificar estruturas, adotar perspectivas múltiplas, reconhecer metáforas e insinuações), criativas (ima- 
ginar diversas interpretações, ter curiosidade, idealizar finais múltiplos) e afetivas (tolerar incertezas enquanto a história se desenvolve, embarcar no clima do enredo), promovendo uma abertura na visão epistemológica do médico, já que passam a ser consideradas e legitimadas múltiplas fontes de saber acerca do paciente, incluindo as informais e subjetivas, muitas vezes consideradas não científicas (p. 516) ${ }^{19}$.

\section{CONCLUSÕES}

Comparando-se o número de projetos pedagógicos que citaram o uso do portfólio e as publicações encontradas, concluí-se que há grande carência de estudos voltados ao processo ensino-aprendizagem nas escolas médicas. Quanto aos achados a respeito da aplicação do portfólio, sobressaem as dificuldades relativas à manutenção do modelo biomédico nas escolas e métodos tradicionais de ensino e avaliação, bem como a falta de motivação e condições para que os docentes se dediquem a transformações que requerem capacitação, coesão e apoio institucional.

O portfólio, segundo as investigações levantadas, vem sendo aplicado enquanto estratégia, instrumento ou dispositivo de avaliação e/ou formação, apresentando as dimensões reflexiva, formativa e somativa. É descrito também como instrumento de comunicação, de armazenamento de informações e de materiais didáticos. Na maioria das situações descritas, vem sendo empregado em estágios e vivências nos serviços de saúde e comunidade.

A adesão à sua aplicação implica grandes desafios, de adoção de metodologias ativas de ensino-aprendizagem e transformação da avaliação e da didática tradicional. Requer das escolas e dos docentes que o utilizam a mudança da cultura avaliativa, o diálogo, o estímulo à autonomia e responsabilidade do estudante. Possibilita levar em conta o crescimento pedagógico do estudante, bem como a complexidade do fazer saúde, as particularidades dos contextos, das escolas e dos sujeitos e a multiplicidade e acelerada mudança dos conhecimentos.

Entendendo o portfólio como facilitador da reconstrução e reelaboração do processo de ensino ao longo de um curso ou de um período de ensino, sua elaboração favorece as interrelações com e entre os professores e com a comunidade e oferece a oportunidade de refletir sobre o progresso dos estudantes em sua compreensão da realidade, ao mesmo tempo em que possibilita introduzir mudanças necessárias nos conteúdos e estratégias educacionais.

Permite que o estudante reflita sobre si mesmo, fixando o conhecimento baseado na compreensão e na subjetividade de todo o processo. Por meio da elaboração de narrativas, o aluno pode selecionar experiências relevantes, articular teoria e prá- tica, e analisar suas vivências. A construção do portfólio resulta em que a ação de aprendizagem seja algo que lhe pertence, ao ter a liberdade de escolher sobre quais situações e conteúdos deve se debruçar para refletir e buscar aprofundamentos.

Trabalhoso e requerente de tempo, dedicação e apoio institucional, o portfólio deve ser considerado não de forma pontual, mas no contexto do ensino e como uma atividade complexa, baseada em elementos de aprendizagem que se encontram relacionados.

Esta revisão demonstrou que ainda há muito a caminhar na reorientação das escolas médicas para o cumprimento das Diretrizes Curriculares, com o propósito de formar profissionais críticos, reflexivos e competentes, para exercer suas funções em resposta ao SUS e à integralidade do cuidado em saúde. Pode-se inferir que as transformações curriculares são pontuais, limitadas a determinadas escolas, disciplinas e contextos. Quanto ao portfólio, constata-se que não há uma padronização quanto a seu uso e ainda há muito despreparo por parte dos professores e na aceitação dos estudantes em relação a esse método.

Observa-se, também, carência de publicações sobre a temática da avaliação e aprendizagem em metodologias ativas e demais indicações de políticas de ensino para as escolas médicas e em saúde.

\section{REFERÊNCIAS}

1. Feuerwerker LCM. Além do discurso de mudança na educação médica: processos e resultados. Editora: Hucitec/ Rede Unida/ABEM, 2002.

2. Schraiber LB. O médico e suas interações: a crise dos vínculos de confiança. São Paulo: Hucitec; 2008.

3. Garcia MAA. Saber, agir e educar: o ensino-aprendizagem em serviços de Saúde. Interface [on line]. 2001. 5(8) [capturado 5 mar 2018]; 89-100. Disponível em: https:/ /dx.doi. org/10.1590/S1414-32832001000100007.

4. Marin MJS et al. O uso do portfólio reflexivo no curso de medicina: percepção dos estudantes. Rev Bras Educ Med [on line]. 2010. 34(2)[capturado em: 05 Mar. 2018]; 191198. Disponível em: http://dx.doi.org/10.1590/S010055022010000200002.

5. Morin E. A cabeça bem feita: repensar a reforma, reformar o pensamento. $5^{\text {a }}$ ed. Rio de Janeiro: Bertrand Brasil, 2001.

6. Cyrino EG, Torrales-Pereira ML. Trabalhando com estratégias de ensino-aprendizado por descoberta na área de saúde: a problematização e a aprendizagem baseada em problema. Cad. Saúde Pública, 2004,20(3): 780-788,2004.

7. Freire P. Pedagogia do oprimido. Rio de Janeiro/São Paulo: Paz e Terra; 63ª ed., 2017. 
8. Gomes AP, Rego S. Paulo Freire: contribuindo para pensar mudanças de estratégias no ensino de medicina. Rev Bras Educ Méd [on line]. 2014. 38(3) [capturado em 5 mar 2018]; 299-307. Disponível em: https://dx.doi.org/10.1590/ S0100-55022014000300003.

9. Stelet BP, Romano VF, Carrijo APB, Junior JET. Portfólio reflexivo: subsídios filosóficos para uma práxis narrativa no ensino médico. Interface [on line].2017. 21(60) [capturado em 4 mar 2018]; 165-176. Disponível em: https:/ /dx.doi. org/10.1590/1807-57622015.0959

10. Sordi MRL, Silva MM. O uso do portfólios na pedagogia universitária: uma experiência em cursos de enfermagem. Interface 2010; 14(35)943-953.

11. Klenowski V. Desarrollo del portfolio para el aprendizaje y la evaluación. Madrid/Espanha: Narcea, S.A. de Ediciones; 2014. p.11-170.

12. Gomes AP, Arcuri MB, Cristel EC, Ribeiro RM, Souza LMBM et al. Avaliação no Ensino Médico: o papel do portfólio nos currículos baseados em metodologias ativas. Rev Bras de Educ Méd[on line]. 2010. 34(3) [capturado em 3 mar. 2018]; 390-396. Disponível em: https:/ /dx.doi. org/10.1590/S0100-55022010000300008.

13. Neves ASC, Guerreiro JMA, Azevedo GR. Avaliando o portfólio do estudante: uma contribuição para o processo de ensino-aprendizagem. Rev da Avaliação da Educ Sup [on line]. 2016. 21(1) [capturado em 3 mar. 2018]; 199-220. Disponível em: https:/ /dx.doi.org/10.1590/S1414-40772016000100010.

14. Alves LP. Portfólios como instrumentos de avaliação dos processos de aprendizagem. In: Anastasiou LCG, Alves LP. Processos de ensinagem na universidade: pressupostos para as estratégias de trabalho em aula. $5^{\mathrm{a}}$ ed. Joinville: Univille; 2005.

15. Bernardi MC, Prado ML, Kempfer SS, Ribeiro KRB, Oliveira SN. Portfólio na avaliação do estudante de graduação na área da saúde: Estudo bibliométrico. Cogitare enferm 2015;20(1)153-160.

16. Boas BMFV. O portfólio no curso de pedagogia: ampliando o diálogo entre professor e aluno. Educação \& Sociedade [on line].2005. 26(90) [capturado em 7 mar. 2018]; 291306. Disponível em: https://dx.doi.org/10.1590/S010173302005000100013

17. Maia MV, Struchiner M. Aprendizagem significativa e o portfólio reflexivo eletrônico na educação médica. Rev Bras Educ Méd [on line]. 2016. 40(4) [capturado em 4 mar. 2018]; 720-730. Disponível em:https:/ /dx.doi.org/10.1590/1981-52712015v40n4e0272014

18. Gontijo ED, Alvim CG, Lima MECC. Manual de avaliação da aprendizagem no curso de graduação em Medici- na. Rev Docência do Ensino Sup [on line]. 2015. 5(1) [capturado em 2 mai. 2018]; 205-325. Disponível em: https:/ / seer.ufmg.br/index.php/rdes/article/view/919/711.

19. Medeiros NS, Santo TR, Trindade EMV, Almeida KJQ. Avaliação do desenvolvimento de competências afetivas e empáticas do futuro médico. Rev Bras Educ Méd[on line]. 2013. 37(4) [capturado em 5 mar. 2018]; 515-525. Disponível em: https://dx.doi.org/10.1590/S010055022013000400007.

20. Cotta RMM, Costa GD. Instrumento de avaliação e autoavaliação do portfólio reflexivo: uma construção teórico-conceitual. Interface [on line]. 2016.20(56) [capturado em 10 mar. 2018];171-183. Disponível em:http://dx.doi. org/10.1590/1807-57622014.1303.

21. Forte MS, Wanderley L, Silva RF, Prado AF. Portfólio reflexivo eletrônico: resultados de um projeto piloto. Rev Bras Educ Méd [on line].2016. 40(2) [capturado em 3 mar. 2018]; 234-244. Disponível em: https: / d dx.doi.org/10.1590/1981-52712015v40n2e00892014.

22. Brasil. Ministério da Educação. Conselho Nacional de Educação. Câmara de Educação Superior. Resolução CNE/CES no 3 de 20 de junho de 2014. Institui diretrizes curriculares nacionais do curso de graduação em Medicina e dá outras providências. Diário Oficial da União. Brasília, 23 Jun. 2014; Seção 1, pp.8-11.

23. Mendes, KDS, Silveira RCCP, Galvão CM. Revisão integrativa: método de pesquisa para a incorporação de evidências na saúde e na enfermagem.Texto contexto - enferm. [on line]. 2008. 17(4) [capturado em 18 jun. 2018]; 758764. Disponível em: http://dx.doi.org/10.1590/S010407072008000400018.

24. Souza MT, Silva MD, Carvalho R. Revisão integrativa: o que é e como fazer. Einstein [on line]. 2010. 8(1/1) [capturado em 4 mar 2018]; 102-106. Disponível em: www.scielo. br/pdf/eins/v8n1/pt_1679-4508-eins-8-1-0102.pdf

25. Domingues RCL, Amaral E, Zeferino AMB. Competência clínica de alunos de Medicina em estágio clínico: comparação entre métodos de avaliação. Rev Bras Educ Méd [on line]. 2010. 34(1) [capturado em 10 mar 2018]; 124131. Disponível em:http://dx.doi.org/10.1590/S010055022010000100015.

26. Aguiar AC, Ribeiro ECO. Conceito e avaliação de habilidades e competência na educação médica: percepções atuais dos especialistas. Rev Bras Educ Méd [on line]. 2010. 34(3) [capturado em 4 mar 2018]; 371-378. Disponível em:http:/ /dx.doi.org/10.1590/S0100-55022010000300006.

27. Claro LBL, Mendes AAA. Uma experiência do uso de narrativas na formação de estudantes de Medicina. In- 
terface [on line]. 2018. 22(65) [capturado em 8 mar. 2018]; 621-630. Disponível em:http://dx.doi.org/10.1590/180757622016.0850.

28. Marin MJS, Caputo VG, Ishida E, Giovanetti JN, Pinto R Teixeira. Aprendendo com a prática: experiência de estudantes da Famema. RevBrasEduc Méd[on line].2007. 31(1) [capturado em 4 mar 2018]; 90-96. Disponível em: https:/ / dx.doi.org/10.1590/S0100-55022007000100012.

29. Silva RF, Chaves IS. Formação reflexiva: representações dos professores acerca do uso de portfólio reflexivo na formação de médicos e enfermeiros. Interface [on line].2008. 12(27) [capturado em 3 mar. 2018]; 721-734. Disponível em:http:/ /dx.doi.org/10.1590/S1414-32832008000400004.

30. Moreto G, Bariani DB, Pinheiro TR, Altisent R, González PB. Uma nova metodologia docente em bioética: experiências com a aplicação do portfólio para estudantes de medicina no brasil. Persona y Bioética2008;12(2)132-144.

31. Cabrera MAS, Turini B, Paccola LBB. O uso de portfólio na prática de atendimento domiciliar a idosos no curso de Medicina. RevBras de Educ Méd [on line].2008. 32(2) [capturado em 4 mar. 2018]; 180-187.Disponível em: https:/ / dx.doi.org/10.1590/S0100-55022008000200005.

32. Prearo AY, Monti FMF, Barragan E. É possível desenvolver a autorreflexão no estudante de primeiro ano que atua na comunidade? Um estudo preliminar. Rev Bras de Educ Méd [on line]. 2012. 36(1) [capturado em 3 mar. 2018]; 24-31.Disponível em: https://dx.doi.org/10.1590/S010055022012000100004.

33. Silva RF, Francisco MA. Portfólio reflexivo: uma estratégia para a formação em medicina. Rev Bras Educ Méd [on line].2009. 33(4)[capturado em 5 mar. 2018]; 562570.Disponível em: http://dx.doi.org/10.1590/S010055022009000400007.
34. Zeferino AMC, Zanolli ML, Antonio MARGM. Experiência da atenção integral à saúde individual e familiar com enfoque na responsabilização, vínculo médico-paciente, ética e profissionalismo no Currículo Médico Integrado. Rev Bras Educ Méd[on line].2012. 36(1/2)[capturado em 5 mar. 2018]; 141-146. Disponível em: http://dx.doi. org/10.1590/S0100-55022012000300020.

35. Fernandes VA, Scucuglia ACB, Gonsaga RAT, Biscegli TS. Contribution of the Activities Diary to the pediatric teaching. Rev Paul Pediatr [on line].2013. 31(3) [capturado em 5 mar 2018]; 366-370. Disponível em: http://dx.doi. org/10.1590/S0103-05822013000300014.

36. Troncon LEA. Avaliação Programática do Estudante: Estratégia Institucional para Melhor Cumprir as Funções da Avaliação Educacional. Revista de Graduação USP[on line].2016. 1(1) [capturado em 9 mar 2018]; 53-58. Disponível em:http:/ /dx.doi.org/10.11606/issn.2525-376X.v1i1p53-58.

\section{CONTRIBUIÇÃO DOS AUTORES}

Ambos os autores participaram de todas as fases do artigo, desde a elaboração do projeto até a redação final.

\section{CONFLITO DE INTERESSES}

Não há conflito de interesses.

\section{ENDEREÇO PARA CORRESPONDÊNCIA}

Maria Alice Amorim Garcia

Rua Dr. Antonio Hossri, 358

Cidade Universitária - Campinas

CEP 13083-370 - SP

E-mail: malicegarcia2@gmail.com 